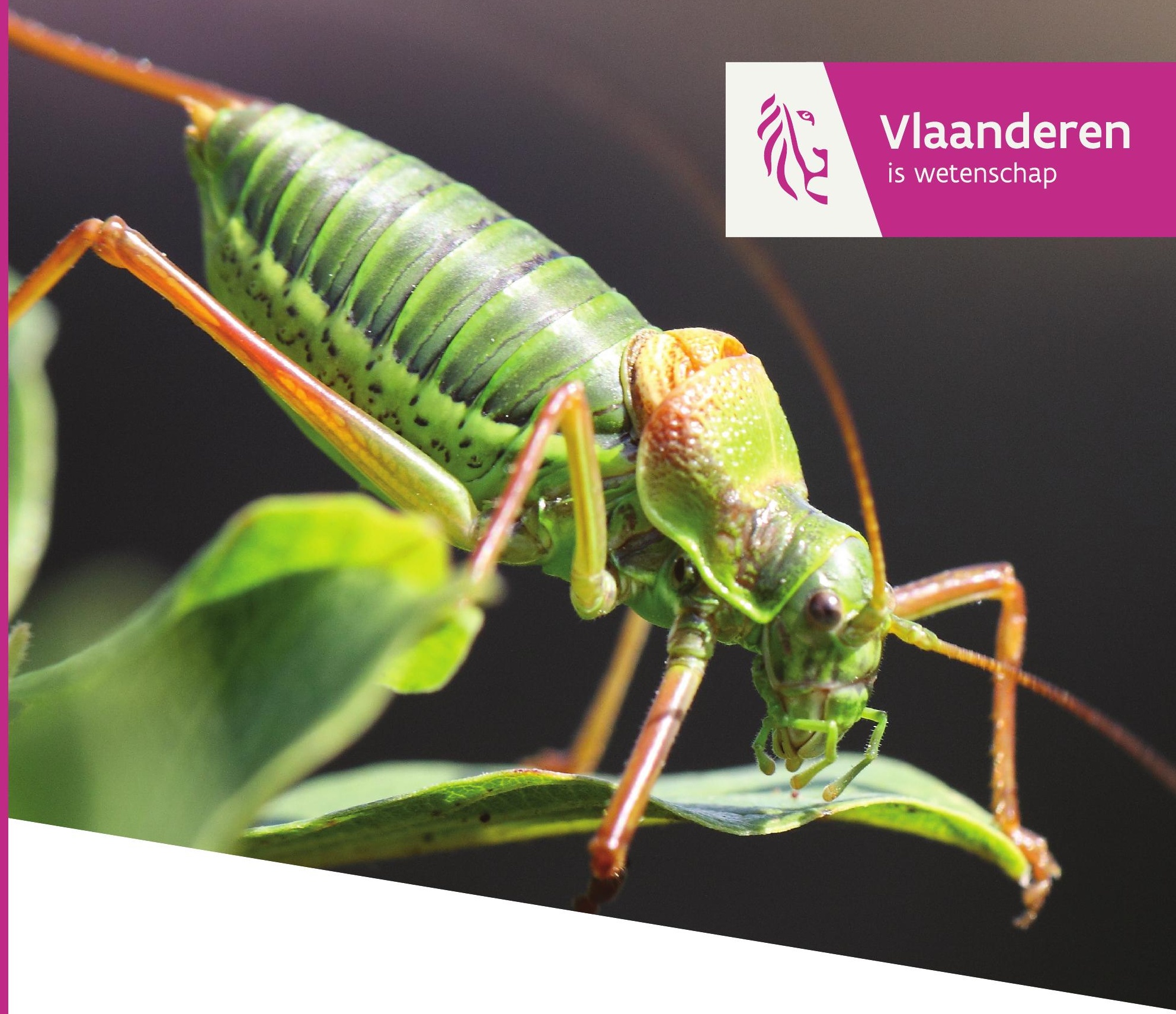

\title{
Monitoringsprotocol sprinkhanen
}

Geert De Knijf, Tim Adriaens, Luc De Bruyn, Dirk Maes, Thierry Onkelinx, Frederic Piesschaert, Marc Pollet, Toon Westra \& Paul Quataert

INSTITUUT

NATUUR- EN BOSONDERZOEK 


\section{Auteurs:}

Geert De Knijf, Tim Adriaens, Luc De Bruyn, Dirk Maes, Thierry Onkelinx, Frederic Piesschaert, Marc Pollet, Toon Westra \& Paul Quataert

Instituut voor Natuur- en Bosonderzoek

Het Instituut voor Natuur- en Bosonderzoek (INBO) is het Vlaams onderzoeks- en kenniscentrum voor natuur en het duurzame beheer en gebruik ervan. Het INBO verricht onderzoek en levert kennis aan al wie het beleid voorbereidt, uitvoert of erin geïnteresseerd is.

\section{Vestiging:}

INBO Brussel

Kliniekstraat 25, B-1070 Brussel

www.inbo.be

e-mail:

geert.deknijf@inbo.be

\section{Wijze van citeren:}

De Knijf G., Adriaens T., De Bruyn L., Maes D., Onkelinx T., Piesschaert F., Pollet M., Westra T. \& Quataert P. (2016). Monitoringsprotocol sprinkhanen. Rapporten van het Instituut voor Natuur- en Bosonderzoek 2016 (INBO.R.2015.10069987). Instituut voor Natuur- en Bosonderzoek, Brussel.

$D / 2015 / 3241 / 261$

INBO.R.2015.10069987

ISSN: 1782-9054

Verantwoordelijke uitgever:

Maurice Hoffmann

Druk:

Managementondersteunende Diensten van de Vlaamse overheid

\section{Foto cover:}

Zadelsprinkhaan (Ephippiger ephippiger), een prioritaire soort voor het Vlaams beleid (@ Geert De Knijf) 


\section{Vlaanderen}

\section{Monitoringsprotocol sprinkhanen}

Geert De Knijf, Tim Adriaens, Luc De Bruyn, Dirk Maes, Thierry Onkelinx, Frederic Piesschaert, Marc Pollet, Toon Westra \& Paul Quataert 


\section{Voorwoord}

Om op een onderbouwde manier te kunnen rapporteren over de verspreiding en trend van Europese Habitat- en Vogelrichtlijnsoorten en de Vlaamse prioritaire soorten is er nood aan een wetenschappelijk en statistisch onderbouwd monitoringnetwerk. Steunend op de eerder gepubliceerde blauwdrukken voor de soortenmonitoring in Vlaanderen (De Knijf et al. 2014), werken we de monitoringmethoden uit, bepalen we het aantal en de selectie van de te monitoren locaties voor de sprinkhanen. Dit monitoringsprotocol stelt de veldwerkcoördinator in staat om het meetnet op te zetten en te starten met de monitoring.

\section{Dankwoord}

In de eerste plaats danken we Natuurpunt Studie en de Sprinkhanenwerkgroep Saltabel voor het ter beschikking stellen van de waarnemingen van de te monitoren sprinkhanen. Luc Crevecoeur bezorgde ons bijkomende informatie over de Zadelsprinkhaan in Limburg. Verder hebben Maurits Vandegehuchte en Bernard Van Elegem (ANB) constructief bijgedragen aan het tot stand komen van dit rapport, waarvoor dank. 


\section{Samenvatting}

Dit rapport beschrijft het protocol voor het monitoringmeetnet sprinkhanen dat zal worden toegepast op twee soorten. De Zadelsprinkhaan (Ephippiger ephippiger) wordt opgevolgd door het aantal zingende mannetjes in een gebied te tellen. Het Schavertje (Stenobothrus stigmaticus) wordt gemonitord door in plots van 10x10 meter alle dieren weg te vangen, het tijdstip van wegvangst te bepalen, te tellen en ter plaatste terug vrij te laten (wegvangstmethode). We verduidelijken hoe voor deze twee soorten het steekproefkader opgesteld werd. Aangezien beide soorten sprinkhanen zeer zeldzaam zijn, gebeurt de monitoring integraal. Per soort geven we vervolgens de lijst van te monitoren gebieden en bespreken we de frequentie waarmee de tellingen moeten gebeuren. Ten slotte verwijzen we naar het dataportaal waar de verzamelde gegevens ingevoerd moeten worden voor verdere analyse.

\section{English abstract}

This report describes the protocol for the monitoring of grasshoppers in Flanders. We present the species that have to be monitored and the field protocol. The Saddle-backed Bushcricket Ephippiger ephippiger must be monitored by counting the number of singing males. The Lesser-mottled Grasshopper Stenobothrus stigmaticus is monitored by capturing and counting all grasshoppers in a plot of 10x10 meter using a depletion method. All individuals are released in situ after identification. We explain how the framework of the monitoring sites has been collated. Since both grasshopper species are very rare, the monitoring covers all known localities. We present the list of monitoring sites and the monitoring frequency. Finally, we refer to the data portal where the collected records must be entered for future analysis. 


\section{Inhoudstafel}

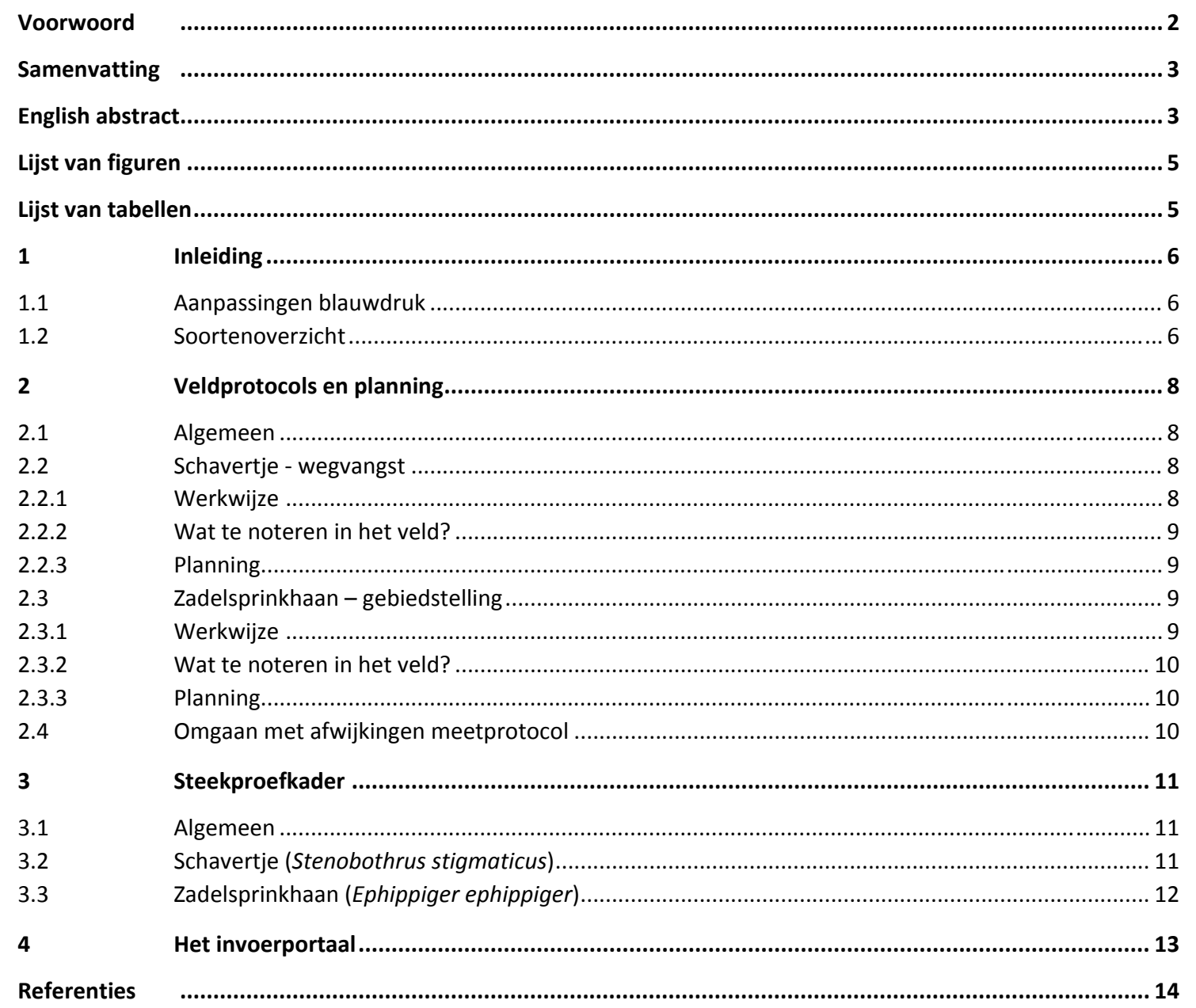




\section{Lijst van figuren}

Figuur 1 Voorbeeld van veldformulier hoe de weggevangen soorten in het veld kunnen genoteerd worden. ........9

Figuur 2 Ligging van de te monitoren gebieden voor het Schavertje in Vlaanderen. ...........................................11

Figuur 3 Ligging van de te monitoren gebieden voor de Zadelsprinkhaan in Vlaanderen....................................12

\section{Lijst van tabellen}

Tabel 1 Overzicht van de te monitoren sprinkhanen met het aantal locaties waar ze na 2010 nog voorkomen, het aantal bezoeken of uit te leggen proefvlakken, de periode waarin de soort moet opgevolgd worden en de methode hoe ze gemonitord moet worden. Tussen haakjes worden de getallen uit de blauwdruk vermeld. 


\section{$1 \quad$ Inleiding}

Voor de ondersteuning van het Vlaamse en Europese natuurbeleid is onderbouwde informatie nodig over de verspreiding en de trends van Vlaams en Europees prioritaire soorten. Om deze informatie zo efficiënt mogelijk te verzamelen en te verwerken, is een goede samenwerking tussen vrijwilligers en natuurverenigingen enerzijds en professionelen anderzijds essentieel (Herremans et al. 2014). Methodieken die hierbij gebruikt worden, werden in De Knijf et al. (2014) als blauwdrukken ontwikkeld voor het opvolgen van de Europese Natura 2000- en Vlaams prioritaire soorten. Voor de gegevensinzameling werken we ook zoveel mogelijk conform internationale standaarden om een maximale vergelijkbaarheid te realiseren. Hier geven we een meer gedetailleerde en praktische invulling van de algemene principes in de blauwdruk. Het huidige document stelt de veldwerkcoördinator in staat om het meetnet op te zetten, veldformulieren en veldkaarten aan te maken, zodat de monitoring kan worden uitgevoerd en de gegevens verzameld en ingevoerd worden in een dataportaal.

\subsection{Aanpassingen blauwdruk}

Ten opzichte van de blauwdruk sprinkhanen (De Knijf \& Adriaens 2014) zijn er slechts minimale veranderingen. Zo komt in een gebied de populatie van de Zadelsprinkhaan ruimtelijk van elkaar gescheiden voor, waardoor we dit gebied nu beschouwen als twee op te volgen gebieden. Van het Schavertje is er ondertussen een populatie verdwenen in Vlaanderen. Bij de Zadelsprinkhaan is het nodig om twee bezoeken per gebied te brengen wat een betere inschatting geeft van de populatiegrootte. Deze wijzigingen zijn terug te vinden in Tabel 1.

Tabel 1 Overzicht van de te monitoren sprinkhanen met het aantal locaties waar ze na 2010 nog voorkomen, het aantal bezoeken of uit te leggen proefvlakken, de periode waarin de soort moet opgevolgd worden en de methode hoe ze gemonitord moet worden. Tussen haakjes worden de getallen uit de blauwdruk vermeld.

\begin{tabular}{lcccc} 
Nederlandse naam (Wetenschappelijke) & \#locaties & \#bezoeken & periode & Methodiek \\
\hline Schavertje (Stenobothrus stigmaticus) & $2(3)$ & 1 & augustus-september & wegvangst \\
Zadelsprinkhaan (Ephippiger ephippiger) & $5(4)$ & $2(1)$ & augustus-september & gebied/auditief \\
\hline
\end{tabular}

\subsection{Soortenoverzicht}

De soorten uit het meetnet voor de Vlaams prioritaire sprinkhanensoorten werden geselecteerd op basis van een inschatting van het relatief belang van Vlaanderen voor de totale instandhouding van de soort, evenals het onder druk staan van beide soorten in West-Europa. Er werden twee soorten weerhouden voor de monitoring van Orthoptera in Vlaanderen. In Tabel 1 geven we een overzicht van de te monitoren sprinkhanen, het aantal te monitoren locaties, de periode en de manier waarop ze gemonitord moeten worden. Voor deze Vlaams prioritaire soorten wil het beleid een goed beeld hebben over de trend van de populatie-aantallen in Vlaanderen. De historische gegevens, ingezameld door de sprinkhanenwerkgroep Saltabel (Adriaens et al. 2016) en de huidige inzameling van data door de sprinkhanenwerkgroep van Natuurpunt en via de invoermodule waarnemingen.be, geven een goed beeld van de verspreiding, en allicht ook van mogelijke veranderingen in areaal in Vlaanderen. De 
huidige data zijn echter onvoldoende om een uitspraak te kunnen maken over de trend van de populatie-aantallen. 


\section{Veldprotocols en planning}

\section{$2.1 \quad$ Algemeen}

De meetvraag die we trachten te beantwoorden met het meetnet sprinkhanen is of de soort in Vlaanderen over een periode van 24 jaar met minstens $25 \%$ afneemt of met $33 \%$ stijgt (Westra et al. 2014). Aangezien beide soorten sprinkhanen op minder dan 30 locaties voorkomen, worden alle locaties integraal opgevolgd.

\subsection{Schavertje - wegvangst}

\subsubsection{Werkwijze}

Populaties van het Schavertje worden opgevolgd, gebruikmakend van de zogenaamde kwantitatieve 'wegvangstmethode' binnen een vooraf bepaald proefvlak (van Veen \& Zeegers 1993). Dit werd ook zo toegepast voor het opvolgen van sprinkhanen in het project Permanente Inventarisatie van Natuur aan de Kust (PINK - Provoost et al. 2015). Hierbij wordt er voor gezorgd dat het proefvlak gelegen is in een vrij homogene vegetatie, bij voorkeur ijl begroeide mosduintjes, vegetatie van het dwerghaververbond of in een borstelgrasland. Binnen het proefvlak van 10x10 m worden alle sprinkhanen manueel weggevangen en in een potje bijgehouden (zorg wel voor voldoende verluchtingsgaten zodat de dieren niet sterven). Dit kan best gericht door elke sprinkhaan, met uitzondering van doornsprinkhanen, die men hoort of ziet weg te vangen in plaats van te 'slepen' in de plot. Dit doet men tot het moment dat gedurende een 10-tal minuten geen sprinkhanen meer opgemerkt worden in het proefvlak. Bij iedere vangst van een sprinkhaan noteert men het tijdstip, soort en geslacht, waarbij het startmoment wordt weergegeven als 0 minuten. Eens alle sprinkhanen weggevangen zijn, worden ze een voor een nogmaals gecontroleerd en terug vrijgelaten in het proefvlak. Het veldwerk wordt door minstens twee personen uitgevoerd waarbij iemand de sprinkhanen vangt en de andere noteert. Hierbij is het van belang dat alle sprinkhanensoorten worden genoteerd die men heeft verzameld en niet enkel Schavertjes. Op die manier kan per soort een curve worden opgesteld die het cumulatief aantal gevangen individuen uitzet ten opzichte van de verstreken tijd. Dergelijke grafiek kent in principe een asymptotisch verloop naar de totale populatiegrootte, althans als de migratie beperkt is. Door alle soorten te noteren in het proefvlak kunnen ook totale dichtheden berekend worden. Het tellen van alle soorten kan ook extra informatie opleveren m.b.t. de representativiteit van de telling. Dit alles gebeurt bij zonnig en warm weer. Tijdens regenbuien en vroeg in de ochtend zijn de meeste sprinkhanen niet actief en worden al snel over het hoofd gezien omdat ze zich verschuilen in nabijgelegen hogere vegetatie.

In de Cabourduinen in De Panne worden, gezien de grootte van het gebied en het ruim verspreid voorkomen van het Schavertje, twee proefvlakken uitgelegd die jaarlijks worden opgevolgd. In de Oostvoornduinen te Koksijde en de Schobbejakshoogte te Brugge komt het Schavertje slechts op een vrij kleine oppervlakte voor waardoor 1 proefvlak per locatie volstaat. Om het proefvlak ook de komende jaren gemakkelijk terug te vinden, is het belangrijk om dit proefvlak grondig te documenteren (Provoost et al. 2015). Indien de komende jaren het proefvlak minder geschuikt wordt, door bv. toenemende vergrassing door lagere graasdruk van konijnen, kan er gebruik gemaakt worden van het principe van 'shifting window', waarbij een proefvlak van $100 \mathrm{~m}^{2}$ binnen een zone van $100 \times 100$ meter wordt uitgelegd in optimaal habitat om steeds een goed beeld te bekomen van de aanwezige populatiegrootte. 


\subsubsection{Wat te noteren in het veld?}

Per proefvlak worden alle weggevangen sprinkhanen genoteerd en van elk gevangen exemplaar van het Schavertje, wordt tevens het tijdstip van vangen genoteerd waarbij de start van het wegvangen van de eerste sprinkhaan wordt genoteerd als tijd 0 min (zie Figuur 1 ).

\begin{tabular}{|c|c|c|c|c|c|c|c|c|c|c|c|c|}
\hline \multicolumn{13}{|l|}{ SOORT --> } \\
\hline Minuut & 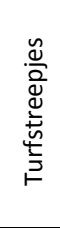 & है & 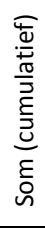 & 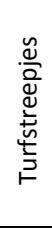 & है & 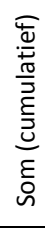 & 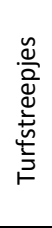 & $\begin{array}{l}\varepsilon \\
n\end{array}$ & 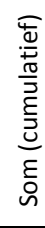 & 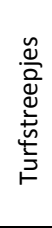 & ह & 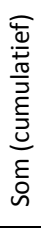 \\
\hline 00 & & & & & & & & & & & & \\
\hline 01 & & & & & & & & & & & & \\
\hline 02 & & & & & & & & & & & & \\
\hline 03 & & & & & & & & & & & & \\
\hline
\end{tabular}

Figur 1 Voorbeeld van veldformulier hoe de weggevangen soorten in het veld kunnen genoteerd worden.

\subsubsection{Planning}

Gezien de hoge jaarlijkse schommelingen in het aantal dieren, een typisch gegeven voor insecten, is het nodig om, indien slechts een beperkte set van locaties $(n=2)$ gekend is, die allemaal jaarlijks op te volgen (integrale opvolging). Bedoeling is om elke locatie jaarlijks eenmaal te onderzoeken in de periode augustus-september.

\subsection{Zadelsprinkhaan - gebiedstelling}

\subsubsection{Werkwijze}

Populaties van de Zadelsprinkhaan kunnen het best opgevolgd worden door binnen een vooraf gedefinieerd gebied alle zingende mannetjes auditief te tellen (Reemer \& Van Hoof 2005). Omdat de wijfjes en de nimfen moeilijk zijn te vinden, zal de hier voorgestelde methode een beeld geven van het aantal zingende mannetjes in een gebied. De frequentie van het geluid van de Zadelsprinkhaan ligt overwegend tussen 15 - $25 \mathrm{kHz}$. Daardoor kan dit gehoord worden tot op een afstand van $45 \mathrm{~m}$ en met een batdetector zelfs tot op een afstand van $55 \mathrm{~m}$ (Eykens 2008). Voor mensen met een slecht gehoor of mensen van boven de 45 jaar is de zadelsprinkhaan moeilijk te horen. Zij kunnen gebruik maken van een batdetector aangezien de geproduceerde frequentie nog net binnen het bereik valt van de batdetector (Eykens 2008). Mannetjes zingen vanuit struiken en lage boompjes en zitten vaak met enkele (twee drie) 
bij elkaar, verspreid over enkele struikjes. Ze roepen dan alternerend zodat het lijkt alsof het een enkel mannetje is dat roept.

Volwassen Zadelsprinkhanen zijn in Nederland en Vlaanderen te vinden tussen eind juli en begin november, met de hoogste aantallen tussen eind augustus en midden september (Kleukers et al. 1997, Reemer \& Van Hoof 2005). De monitoring van de Zadelsprinkhaan dient te gebeuren tussen 25 augustus en 15 september. Hierbij wordt elk gebied gedurende twee uur onderzocht op het aantal zingende mannetjes.

Het tijdstip waarop de dieren geluid maken is sterk afhankelijk van de plaatselijke weersomstandigheden. Ideale weersomstandigheden om de Zadelsprinkhaan te tellen zijn zonnig, warm weer $\left(\min 17^{\circ} \mathrm{C}\right.$ ). Vermoedelijk hangt de zangactiviteit sterk samen met de temperatuur. Mits goed weer kan er eind augustus geteld worden tussen 10 en 16 uur. Later in het seizoen verlaat het aanvangsuur (Eykens 2008) en nemen de mannetjes genoegen met steeds lagere temperaturen (Reemer \& Van Hoof 2005, Eykens 2008).

Binnen het afgebakende gebied wordt een vast parcours gelopen dat steeds gevolgd wordt bij elke telling. Een gps of smartphone kunnen hierbij nuttig zijn om het vaste traject op te slaan. De lengte van het parcours is afhankelijk van de grootte van het gebied. Er worden minimum twee tellingen uitgevoerd, met minimum 5 dagen tussen de tellingen.

Bij het doorlopen van het gebied concentreert men zich op de Zadelsprinkhaan. Indien de teller meer ervaring heeft, is het wenselijk om niet enkel deze doelsoorten te tellen, maar alle sprinkhanen die waargenomen worden in het gebied en dit zo ook in te geven in meetnetten.be.

\subsubsection{Wat te noteren in het veld?}

Per telgebied worden alle roepende mannetjes genoteerd, evenals het begin- en einduur van de telling. Ook wordt er steeds vermeld of er gebruik werd gemaakt van een batdetector.

\subsubsection{Planning}

Gezien het zeer beperkt aantal locaties $(n=5)$ waar de Zadelsprinkhaan momenteel voorkomt, worden alle locaties jaarlijks opgevolgd (integrale opvolging). Door de variabele ontwikkelingsduur van de eieren kunnen de aantallen in het ene jaar namelijk sterk verschillen van die in het jaar daarna. Daarom is het wenselijk de aantallen jaarlijks op te volgen. Bedoeling is om elke locatie jaarlijks tweemaal te bezoeken, tussen 25 augustus en 15 september.

\subsection{Omgaan met afwijkingen meetprotocol}

Het is mogelijk dat door omstandigheden een bepaalde locatie niet (meer) toegankelijk is (bv. eigenaar geeft geen toestemming om terrein te betreden), het terrein is niet meer geschikt voor de soort (bv. heide is teveel verbost), of dat de soort er niet (meer) wordt aangetroffen (soort werd niet waargenomen). Hoe om te gaan met dergelijke situaties wordt omschreven in Onkelinx et al. (2016). 


\section{Steekproefkader}

\subsection{Algemeen}

Op basis van de puntwaarnemingen uit www.waarnemingen.be werd per soort een lijst met de gebieden opgemaakt waarin populaties van beide soorten gedurende de periode 2010-2015 aanwezig waren (steekproefkader). Bijkomend werden de gegevens uit de periode 2000-2009 bekeken en beoordeeld op de mogelijkheid van het voorkomen van nog bijkomende populaties. Dit leverde echter geen bijkomende populaties op. Aangezien het bij deze soorten telkens om minder dan 30 populaties gaat, gebeurt de monitoring integraal (Westra et al. 2014).

\subsection{Schavertje (Stenobothrus stigmaticus)}

Populaties van het Schavertje in Vlaanderen zijn beperkt tot drie gebieden in West-Vlaanderen. In de begroeide mosduinen van de Cabourduinen (korte, schrale, grazige vegetatie), komt ze samen met Snortikker (Chorthippus mollis) plaatselijk zeer algemeen voor. Hier worden 2 plots opgevolgd. Een tweede populatie bevindt zich in de Oostvoornduinen waar ze in (zeer) laag aantal voorkomt. In het stuifzandgebied Schobbejakshoogte komt een (zeer) kleine populatie voor in een complex van dwerghavergrasland en struisgrasvegetatie (Tabel 2; Figuur 2).

Tabel 2 Gebieden, gemeenten en provincie waarin het Schavertje gemonitord moet worden.

\begin{tabular}{lcl} 
Gebied & Gemeente & Provincie \\
\hline 1. Cabourduinen 1 & De Panne & West-Vlaanderen \\
2. Cabourduinen 2 & De Panne & West-Vlaanderen \\
3. Schobbejakshoogte & Brugge & West-Vlaanderen \\
4. Oostvoornduinen & Koksijde & West-Vlaanderen \\
\hline
\end{tabular}

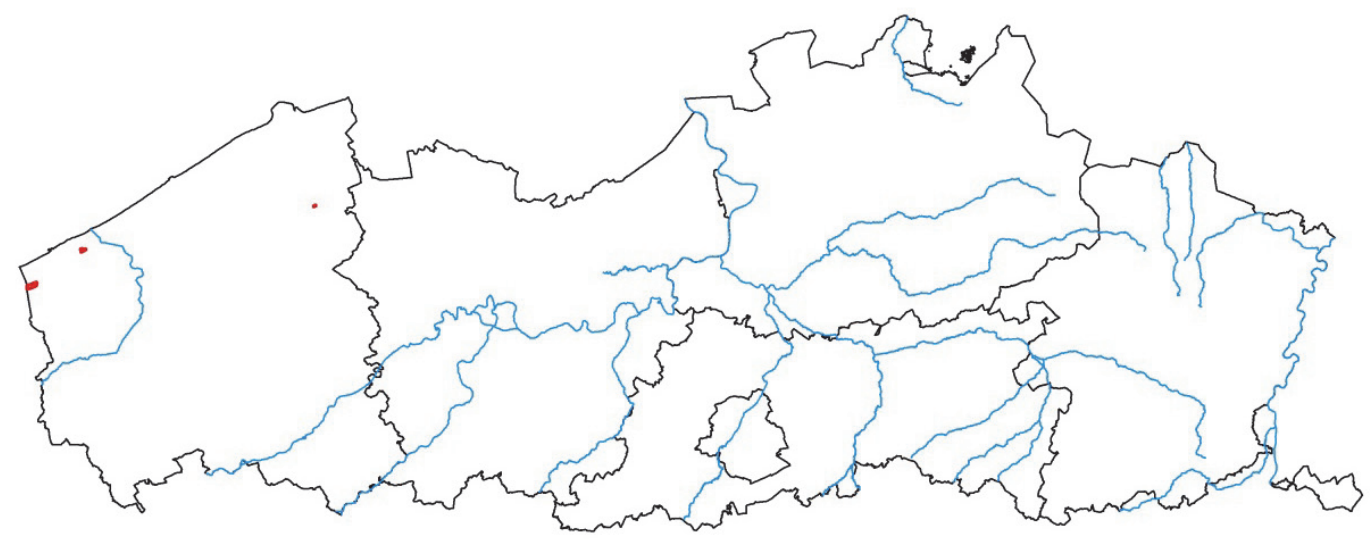

Figur 2 Ligging van de te monitoren gebieden voor het Schavertje in Vlaanderen. 


\subsection{Zadelsprinkhaan (Ephippiger ephippiger)}

De Zadelsprinkhaan moet in vijf gebieden gemonitord worden in Vlaanderen (Tabel 3; Figuur 3). Deze bevinden zich allemaal op de oostkant van het Kempens plateau. Op de Mechelse Heide bevinden zich ruimtelijk twee populaties die van elkaar gescheiden zijn door de een zandgroeve.

Tabel 3 Gebieden, gemeenten en provincie waarin de Zadelsprinkhaan gemonitord moet worden.

\begin{tabular}{lcc} 
Gebied & Gemeente & Provincie \\
\hline 1. Opglabekerzavel & Genk & Limburg \\
2. Mechelse Heide noord & Maasmechelen & Limburg \\
3. Mechelse Heide zuid & Maasmechelen & Limburg \\
4. Kikbeek & Maasmechelen & Limburg \\
5. Heiderbos & As & Limburg \\
\hline
\end{tabular}

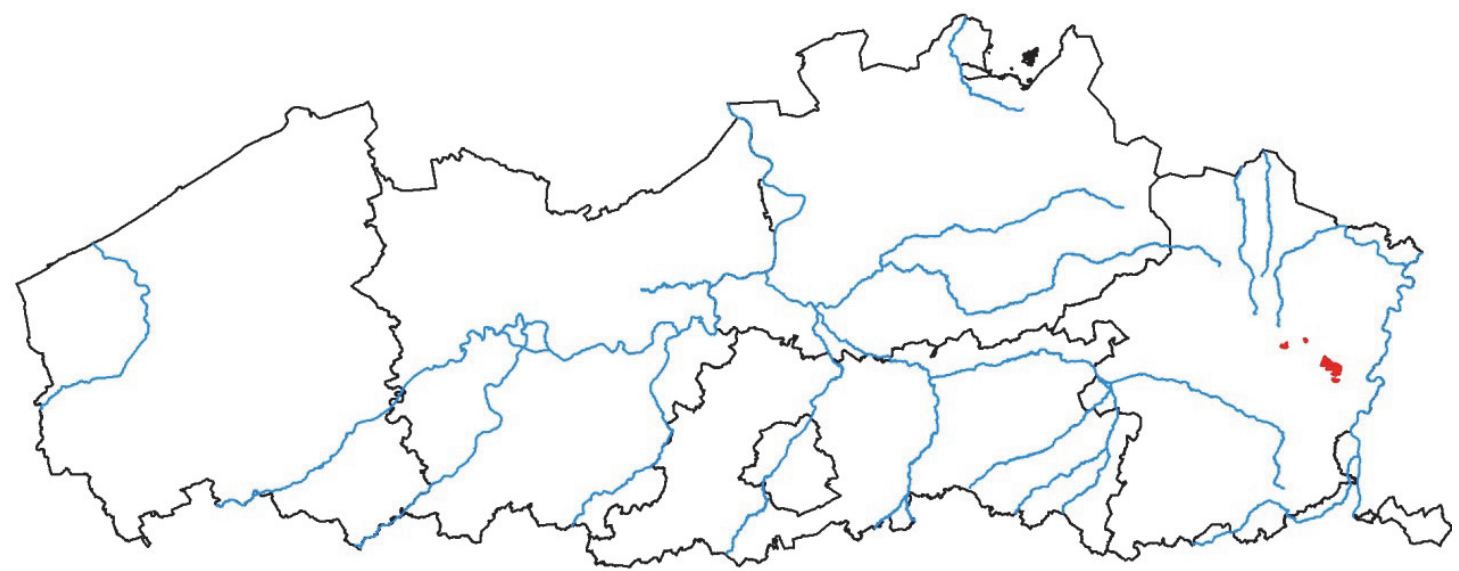

Figuur 3 Ligging van de te monitoren gebieden voor de Zadelsprinkhaan in Vlaanderen. 


\section{$4 \quad$ Het invoerportaal}

Via de webapplicatie www.meetnetten.be kan een veldwerkcoördinator het veldwerk plannen en opvolgen. De vrijwilligers voeren daar ook hun tellingen in. Een handleiding voor het portaal is beschikbaar op www.meetnetten.be. 


\section{Referenties}

Adriaens T., Decleer K., Devriese H., Lock K., Lambrechts J., San Martin y Gomez G., Piesschaert F., Maes D., Vandenborre J., Van Hoey S., Brosens D., Sprinkhanenwerkgroep Saltabel 2016. Saltabel, a database on the distribution and faunistics of Orthoptera in Belgium. doi:10.15468/1rcpsq. Online op http://www.gbif.org/dataset/76cc7230-76b6-4763-9caf-22626b29c0a6

De Knijf G., Westra T., Onkelinx T., Quataert P. \& Pollet M. 2014. Monitoring Natura 2000-soorten en overige soorten prioritair voor het Vlaams beleid. Blauwdrukken soortenmonitoring in Vlaanderen. Rapporten van het Instituut voor Natuur- en Bosonderzoek INBO.R.2014.2319355. Instituut voor Natuur- en Bosonderzoek, Brussel.

De Knijf G. \& Adriaens T. 2014. Blauwdruk sprinkhanen. In: De Knijf G., Westra T., Onkelinx T., Quataert P. \& Pollet M. (eds.) Monitoring Natura 2000-soorten en overige soorten prioritair voor het Vlaams beleid. Blauwdrukken soortenmonitoring in Vlaanderen. Instituut voor Natuur- en Bosonderzoek, Brussel. 125-134.

Eykens C. 2008. Gedrag van de zadelsprinkhaan (Ephippiger ephippiger) in Limburg. Masterproef in de biowetenschappen: Voedingsleer. Katholieke Hogeschool Kempen, Geel.

Herremans M., De Knijf G., Hansen K., Westra T., Vanreusel W., Martens E., Van Gossum H., Anselin A., Vermeersch G. \& Pollet M. 2014. Monitoring van beleidsrelevante soorten in Vlaanderen met inzet van vrijwilligers. Rapporten van het Instituut voor Natuur- en Bosonderzoek INBO.R.2014.1628917. Instituut voor Natuur- en Bosonderzoek, Brussel.

Kleukers R., van Nieukerken E., Odé B., Willemse L. \& Van Wingerden W. 1997. De sprinkhanen en krekels van Nederland (Orthoptera). Nederlandse Fauna I. Nationaal Natuurhistorisch Museum, KNNV en European Invertebrate Survey-Nederland, Leiden.

Onkelinx T., De Knijf G., Maes D., De Bruyn L. \& Westra T. 2016. Omgaan met afwijkingen op een meetnetprotocol. Rapporten van het Instituut voor Natuur- en Bosonderzoek INBO.R.2016.xxx. Instituut voor Natuur- en Bosonderzoek, Brussel.

Provoost S., Van Gompel W., Vercruysse W., Packet J., Denys L. 2015. Permanente Inventarisatie van de Natuurreservaten aan de Kust, PINK II: Eindrapport periode 2012-2014. Rapport van het Instituut voor Natuur- en Bosonderzoek 19, Brussel.

Reemer M. \& Van Hoof P.H. 2005. Beschermingsplan Zadelsprinkhaan en Kleine wrattenbijter in Gelderland. EIS-Nederland, Leiden \& Bureau Natuurbalans - Limes Divergens BV, Nijmegen.

van Veen T. \& Zeegers Th. 1988. Insekten basisboek. Jeugdbondsuitgeverij, Utrecht.

Westra T., Quataert P. \& Onkelinx T. 2014b. Inleiding tot de blauwdrukken. In: Westra T., De Knijf G. \& Pollet M. (eds.) Monitoring Natura 2000-soorten en overige soorten prioritair voor het Vlaams beleid. Blauwdrukken soortenmonitoring in Vlaanderen. Instituut voor Natuur- en Bosonderzoek, Brussel. 10-24. 